\title{
QUALIDADE MICROBIOLÓGICA DO LEITE COMERCIALIZADO NO MUNICÍPIO DE CURITIBA, PARANÁ
}

\section{MICROBIOLOGICAL QUALITY OF THE COMMERCIALIZED MILK IN THE CITY OF CURITIBA, PARANÁ}

\author{
YOSHISUKI, Priscilla Yuri'; COGO, Laura Lúcia ${ }^{2}$
}

1. Acadêmica do Curso de Farmácia das Faculdades Integradas do Brasil. Curitiba (PR). E-mail: pri.1906@hotmail.com

2. Professora Doutora do Curso de Farmácia das Faculdades Integradas do Brasil. Farmacêutica do Laboratório de Bacteriologia do Hospital de Clínicas da Universidade Federal do Paraná.

\section{RESUMO:}

O leite é considerado um alimento altamente nutritivo, sendo constituído, dessa forma, em um excelente meio de cultura para o crescimento de microrganismos patógenos e deteriorantes. O objetivo deste trabalho foi pesquisar a presença de Salmonella sp, coliformes totais e coliformes termotolerantes, e realizar a contagem de bactérias aeróbias mesófilas em amostras de leite pasteurizado e UHT comercializados no município de Curitiba/PR. Foram analisadas 30 amostras de leite, sendo 5 amostras de cada marca, das quais 3 marcas eram de leite pasteurizado tipo $\mathrm{C}$ e 3 marcas de leite UHT. Os resultados obtidos demonstraram que o leite pasteurizado e UHT apresentaram valores dentro do estabelecido pela legislação vigente e as amostras consideradas em condições higiênico-sanitárias adequadas, não oferecendo riscos à saúde da população.

Palavras-chave: Leite pasteurizado, leite UHT, mesófilos, coliformes, Salmonella sp

\section{ABSTRACT:}

Milk is considered a highly nutritional food and constituting, for this same reason, in an excellent culture medium for the growth of deteriorating and pathogenic microrganisms. The objective of this work was to evaluate the presence of Salmonella sp, total coliforms and thermotolerant coliforms, besides the counting of aerobic bacteria mesophilics in samples of pasteurized and UHT milk commercialized in the city of Curitiba/PR. It was analyzed 30 samples of milk, being 5 samples for each mark, where 3 marks were of pasteurized type $\mathrm{C}$ milk and 3 marks of UHT milk. The obtained results demonstrated that pasteurized and UHT milk presented values according to the established for the current law and the samples considered in adjusted hygienic-sanitary conditions, not offering risks to the health of the population.

Key words: Pasteurized milk, UHT milk, mesophilic, coliforms, Salmonella sp 


\section{INTRODUÇÃO}

O leite é considerado um alimento com grande valor nutricional na dieta humana, pois possui em sua composição aproximadamente $87,3 \%$ de água e $12,7 \%$ de sólidos totais, sendo estes distribuídos em proteínas totais, gordura, lactose, minerais e vitaminas (SGARBIERI, 2005). Por esta mesma razão, apresenta-se como um excelente meio de cultura para o crescimento de microrganismos patogênicos e deteriorantes (FRANCO; LANDGRAF, 2008).

Os leites comercializados podem ter vida útil longa, chamado de leite UHT ou UAT (Ultra Alta Temperatura) ou ter vida útil curta, denominado leite pasteurizado (PEREDA et al., 2005). Para sua obtenção, o primeiro, após devidamente homogeneizado, é submetido a uma temperatura de $130^{\circ} \mathrm{C}$ entre 2 a 4 segundos através de um processo térmico de fluxo contínuo, sendo resfriado a seguir a uma temperatura de até $32^{\circ} \mathrm{C}$ e envasado em embalagens estéreis e completamente fechadas (BRASIL, 1997). O segundo é submetido a um tratamento térmico entre a temperatura de $72 \mathrm{a} 75^{\circ} \mathrm{C}$ durante 15 a 20 segundos, seguido de resfriamento imediato em temperatura até $4^{\circ} \mathrm{C}$ e posterior envase, através de condições que diminuam sua contaminação (BRASIL, 2002).

O leite pasteurizado pode ser diferenciado em tipo A, B e C, de acordo com a carga microbiana, o tipo de ordenha e o beneficiamento. Os leites tipo $A$ e $B$ são de ordenha mecânica, onde o tipo A é pasteurizado e embalado em locais denominados Granjas Leiteiras e o B é transportado sob refrigeração para laticínios, onde ocorrerá sua pasteurização. O leite tipo $C$ é de ordenha manual e apresenta uma contagem de microrganismos maior, devido o seu transporte aos laticínios ser realizado em temperatura ambiente (BRASIL, 2002; CARVALHO, 2010).

As características microbiológicas do leite representam um dos principais parâmetros utilizados para identificar a sua qualidade, podendo fornecer informações sobre as condições higiênico-sanitárias, desde a sua produção até seu armazenamento e distribuição para consumo. Entre os principais microrganismos que indicam a qualidade do leite, encontram-se os aeróbios mesófilos e os coliformes totais (FRANCO; LANDGRAF, 2008).

Os microrganismos aeróbios mesófilos são aqueles que têm a capacidade de crescer em temperaturas entre $35-37^{\circ} \mathrm{C}$ em situações de aerobiose. Os coliformes totais são aqueles compostos por bactérias da família Enterobacteriaceae com tendência a fermentar a lactose produzindo gás, quando incubados a $35-37^{\circ} \mathrm{C}$. Neste grupo, Salmonella representa um dos microrganismos mais relacionados em casos de doenças de origem alimentar e sua presença pode causar graves toxinfecções alimentares (FRANCO; LANDGRAF, 2008). Na maioria das vezes, Salmonelose relacionada à laticínios é descrita como sendo causada pelo leite cru ou por processo 
de pasteurização ineficaz (FRANCO; LANDGRAF, 2008; SALVADOR et al., 2012).

O presente trabalho teve como objetivo determinar a qualidade microbiológica do leite pasteurizado e UHT em comparação com a legislação vigente, visto que diversas pesquisas demonstraram a ocorrência desses produtos fora dos padrões microbiológicos adequados.

\section{MATERIAL E MÉTODOS}

\subsection{Amostras}

Foram avaliadas 15 amostras de leite UHT integral e 15 amostras de leite pasteurizado do tipo $\mathrm{C}$, de seis marcas diferentes, sendo cinco amostras de cada marca e com o mesmo lote. As amostras foram obtidas em supermercados de Curitiba/PR durante o período de setembro a outubro de 2013 e encaminhadas ao Laboratório de Bacteriologia do Hospital de Clínicas da Universidade Federal do Paraná.

\subsection{Análise microbiológica}

Em todas as amostras de leite foram realizadas pesquisa de Salmonella sp, coliformes totais e termotolerantes, além da contagem e caracterização das bactérias aeróbias mesófilas.

O leite pasteurizado foi processado assim que o material foi recebido ao laboratório, enquanto que as embalagens fechadas do leite UHT foram incubadas a uma temperatura de 35 a $37^{\circ} \mathrm{C}$ durante sete dias para posteriormente serem realizadas as análises (BRASIL, 2001).

Para análise de bactérias mesófilas, coliformes totais e termotolerantes foi preparada uma diluição inicial adicionando-se $25 \mathrm{~mL}$ de cada amostra em $225 \mathrm{~mL}$ de água peptonada a $0,1 \%$, sendo esta a diluição $10^{-1}$. A partir desta foram efetuadas diluições seriadas até $10^{-3}$, transferindo $1 \mathrm{~mL}$ da primeira diluição para tubos contendo 9 $\mathrm{mL}$ de água peptonada a $0,1 \%$ (BRASIL, 2003).

Na pesquisa de bactérias aeróbias mesófilas foram semeados $0,1 \mathrm{~mL}$ de cada diluição em placas contendo Ágar Padrão para Contagem (PCA), seguida de incubação a $35^{\circ} \mathrm{C}$ por 48 horas e os resultados liberados em UFC/mL (BRASIL, 2003). Após a contagem bacteriana, foram isoladas diferentes colônias de microrganismos que foram submetidas à coloração de Gram e consequente classificação através de suas características morfo-tintoriais.

Para a pesquisa de coliformes totais realizou-se o teste presuntivo utilizando três séries de três tubos de Caldo Lauril Sulfato Triptose para cada diluição, sendo que em cada um dos tubos foi inoculado $1 \mathrm{~mL}$ das diluições $10^{-1}, 10^{-2}$ e $10^{-3}$. As três séries 
foram incubadas a $35 \pm 0,5^{\circ} \mathrm{C}$ por 48 horas e a presença dos coliformes foi confirmada pela formação de gás. Para o teste confirmatório de coliformes totais e coliformes termotolerantes, foram utilizados tubos contendo Caldo Verde Brilhante (BGBL) e Caldo Escherichia coli (EC), respectivamente. As amostras positivas foram separadas e uma alçada de cada foi inoculada em ambos os caldos. Os tubos de BGBL foram incubados a $35 \pm 0,5^{\circ} \mathrm{C}$ por 24 a 48 horas, enquanto que os tubos de EC foram incubados a $45,5 \pm 0,2^{\circ} \mathrm{C}$ por 24 horas. Os resultados positivos foram enquadrados na tabela e expressos em NMP/mL (BRASIL, 2003).

Na pesquisa de Salmonella sp, $25 \mathrm{~mL}$ de cada amostra foram inoculados em $225 \mathrm{~mL}$ de água peptonada a $0,1 \%$ e incubadas a $37 \pm 1^{\circ} \mathrm{C}$ por $18 \pm 2$ horas. Destas diluições, $0,1 \mathrm{~mL}$ foram transferidos para tubos contendo Caldo Rappaport, seguidos de incubação a $41,5 \pm 1^{\circ} \mathrm{C}$ por $24 \pm 3$ horas, e $1 \mathrm{~mL}$ da mesma diluição foram transferidos para Caldo Tetrationato com $0,2 \mathrm{~mL}$ de lugol e incubados a $37 \pm 1^{\circ} \mathrm{C}$ por 24 \pm 3 horas. Através de triplacas contendo os meios XLD, cromogênico e Verde Brilhante foram realizados plaqueamentos diferenciais transferindo uma alçada de cada um dos tubos para as placas, seguidas de incubação por $37 \pm 1^{\circ} \mathrm{C}$ por $24 \pm 3$ horas. Os resultados foram expressos em presença de Salmonella sp/25 mL (BRASIL, 2003).

\section{RESULTADOS E DISCUSSÃO}

Por ser um produto que apresenta uma composição propícia para o desenvolvimento de microrganismos deteriorantes e patogênicos, existe a necessidade de se verificar a qualidade microbiológica dos leites existentes no mercado. A pesquisa tem como intuito analisar as condições do produto para consumo, evitando riscos à saúde do consumidor através de agentes patogênicos, além de garantir as características físico-químicas e organolépticas do produto (NERO et al., 2000).

A análise microbiológica das amostras de leite UHT demonstrou ausência total de bactérias aeróbias mesófilas, Salmonella sp, coliformes totais e coliformes termotolerantes, apresentando-se em conformidade com a legislação em vigor.

Esta afirma que as embalagens fechadas do produto, após serem incubadas por sete dias a uma temperatura de $35-37^{\circ} \mathrm{C}$, não devem conter microrganismos patogênicos e que causem mudanças físicas, químicas e organolépticas (BRASIL, 2001).

Os resultados encontrados neste trabalho assemelham-se com os obtidos por Nascentes et al. (2012), que ao analisarem bactérias aeróbias mesófilas e coliformes, não encontraram nenhum crescimento destes microrganismos. Outros pesquisadores (DOMARESKI et al., 2010) ao avaliarem leites UHT comercializados em três países do Mercosul, sendo eles Brasil, Argentina e Paraguai, encontraram, respectivamente, 
$37,5 \%, 62,5 \%$ e $12,5 \%$ de bactérias aeróbias mesófilas presentes no produto, estando em desacordo com os critérios microbiológicos estabelecidos para o leite UHT. Bersot et al. (2010) ao pesquisar microrganismos mesófilos em leite submetido a ultra alta temperatura, detectou aproximadamente $24 \%$ de amostras fora do padrão, diferindo do resultado obtido neste trabalho.

No método de ultra pasteurização deve ocorrer a eliminação de todos os microrganismos presentes no leite e ao se elevar a uma temperatura de aproximadamente $130^{\circ} \mathrm{C}$ e reduzir o tempo de tratamento a poucos segundos, aumenta-se o efeito esporicida. Cabe ressaltar que o leite deve ser coletado em condições de higiene, pois é a sua carga bacteriana inicial que irá determinar a qualidade da matéria-prima obtida e, consequentemente, a qualidade dos seus produtos derivados (PEREDAet al., 2005; CARVALHO, 2010).

Em relação à avaliação microbiológica das amostras de leite pasteurizado, não foram detectadas presença de coliformes totais e termotolerantes, assim como Salmonella sp, estando em conformidade com a legislação brasileira vigente para leite pasteurizado (BRASIL, 2001).

A presença de microrganismos aeróbios mesófilos foi observada em todas as amostras e os resultados encontram-se expressos na Tabela 1.

TABELA 1 - CONTAGEM E CARACTERIZAÇÃO DE BACTÉRIAS AERÓBIAS MESÓFILAS PRESENTES NAS AMOSTRAS DE LEITE PASTEURIZADO.

\begin{tabular}{lccc}
\hline & Marca A & Marca B & Marca C \\
\hline Cocos Gram-positivos & $4,5 \times 10^{3}$ & $1,78 \times 10^{3}$ & $6,0 \times 10^{3}$ \\
Bacilos Gram-positivos & $6,55 \times 10^{3}$ & $2,14 \times 10^{3}$ & $3,04 \times 10^{3}$ \\
Bacilos Gram-negativos & $0,5 \times 10^{3}$ & ---- & $0,28 \times 10^{3}$ \\
\hline Total $^{*}$ & $\mathbf{1 , 1 5 \times 1 0 ^ { 4 }}$ & $\mathbf{3 , 9 2} \times \mathbf{1 0}$ & $\mathbf{9 , 3 2} \times \mathbf{1 0}$
\end{tabular}

* Os valores totais representam as médias dos resultados obtidos nas análises microbiológicas.

Apesar de haver crescimento de bactérias mesófilas nas amostras de leite pasteurizado, estas se encontram dentro do valor de referência estabelecido, sendo a contagem total máxima permitida de $2,0 \times 10^{4} \mathrm{UFC} / \mathrm{mL}$ (APHA, 1992).

Estes resultados assemelham-se aos obtidos por Souza (2010), que ao analisar a presença de mesófilas, Salmonella sp e coliformes totais e termotolerantes obteve $100 \%$ das amostras dentro do padrão estabelecido.

Porém, pesquisa realizada por Tamanini et al. (2007) em leite do tipo C pasteurizado diferem dos resultados obtidos, apresentando 3,7\% das amostras contendo contagem de aeróbios mesófilos superiores ao preconizado pela legislação e 
$30 \%$ das amostras apresentando coliformes totais acima do tolerado. Valores aumentados para coliformes totais, coliformes termotolerantes e bactérias mesófilas também foram relatados por outros autores (SILVA et al., 2008; BRICIO et al., 2005).

AFigura 1 apresenta os resultados obtidos pela coloração de Gram, através do isolamento das colônias de microrganismos aeróbios mesófilos.

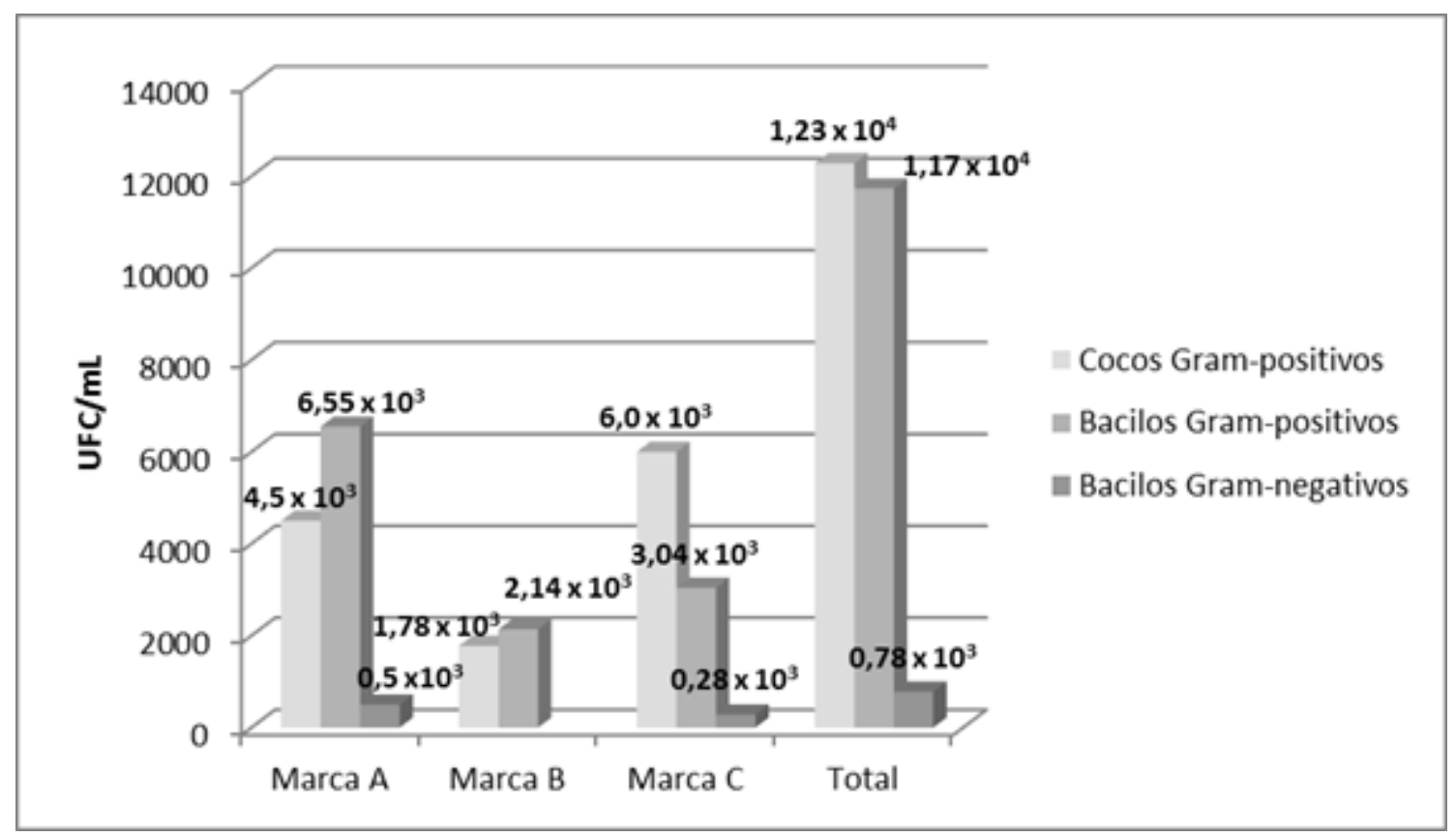

\section{FIGURA 1 - CARACTERIZAÇÃO MORFO-TINTORIAL DAS BACTÉRIAS MESÓFILAS ENCONTRADAS NAS AMOSTRAS DE LEITE PASTEURIZADO.}

Através dos resultados encontrados na coloração, pôde ser observada uma predominância de cocos Gram-positivos, seguida de bacilos Gram-positivos e posteriormente por bacilos Gram-negativos. A maior resistência das bactérias Grampositivas ao calor, em relação às Gram-negativas, é bastante conhecida. Entre as bactérias Gram-positivas, os cocos são geralmente, mais resistentes ao calor do que bastonetes não formadores de esporos (JAY, 2005).

O processo de pasteurização elimina os microrganismos patogênicos, porém os microrganismos termodúricos podem sobreviver a este processo, entre eles estão bactérias esporuladas, bactérias termófilas não-esporuladas (alguns gêneros de Lactobacillus e Streptococcus) onde a termorresistência é maior do que nas bactérias mesófilas, e algumas bactérias mesófilas que possuem termorresistência anormalmente elevada. Com exceção de algumas cepas presentes em Bacillus e Enterococcus, esses microrganismos não causam problemas relacionados a vida útil do leite pasteurizado, pois não possuem a capacidade de se proliferarem à temperatura 
de refrigeração, entre 6 a $8^{\circ} \mathrm{C}$ (PEREDA et al., 2005).

\section{CONCLUSÃO}

Os dados relatados nesse trabalho demonstraram que o material apresentado para consumo na região de Curitiba/PR não favorecem risco à saúde humana, por não apresentarem patógenos e bactérias em quantidade suficiente para degradação do leite e evidenciando que os processos de pasteurização e ultrapasteurização são aplicados de forma eficaz, evitando o crescimento de microrganismos indesejáveis.

\section{AGRADECIMENTOS}

À Laborclin Produtos para Laboratórios Ltda pelo fornecimento dos meios de cultura específicos para a elaboração do projeto, tornando possível a realização do trabalho.

\section{REFERÊNCIAS}

APHA. Committee on microbiological methods for foods. Compendium of methods for the microbiological examination of foods. Washington: American Public Health Association, 1992.

BERSOT, L.S.; GALVÃO, J.A.; RAYMUNDO, N.K.L.; BARCELLOS, V.C.; PINTO, J.P.A.N.; MAZIERO, M.T. Avaliação microbiológica e físico-química de leites UHT produzidos no Estado do Paraná - Brasil. Semina: Ciências Agrárias, Paraná: Londrina, v. 31, n. 3, p. 645-652, jul./set. 2010.

BRASIL. Portaria $n^{\circ} .370$ de 4 de setembro de 1997. Regulamento técnico de identidade e qualidade do leite UAT (UHT). Diário Oficial a União. Brasília, 08 set. 1997. Seção 1, p. 1-3.

BRASIL. Instrução Normativa $n^{\circ} .51$ de 18 de setembro de 2002. Regulamentos Técnicos de Produção, Identidade e Qualidade do Leite tipo A, do Leite tipo B, do Leite tipo C, do Leite Pasteurizado e do Leite Cru Refrigerado e o Regulamento Técnico da Coleta de Leite Cru Refrigerado e seu Transporte a Granel. Diário Oficial da União. Brasília, 20 set. 2002. Seção 1, p. 1-55.

BRASIL. Instrução Normativa $n^{\circ} .62$ de 26 de agosto de 2003. Análises microbiológicas para controle de produção de origem animal e água. Diário Oficial da União, Brasília, 18 set. 2003 . Seção 1, p. 14. 
BRASIL. Resolução-RDC n. 12 de 02 de janeiro de 2001. Regulamento técnico sobre padrões microbiológicos para alimentos. Diário Oficial da União, Brasília, 10 jan. 2001. Seção 1, p.1-48.

BRICIO, S.M.L; SILVA, C.G.; FINGER, R.M. Qualidade bacteriológica do leite pasteurizado tipo $C$ produzido no estado do Rio de Janeiro. R. bras. Ci. Vet., v. 12, n. 1/3, p. 124-126, jan./dez. 2005.

CARVALHO, I.T. Microbiologia dos Alimentos. Pernambuco: Recife, 2010. Disponível em:

<http://redeetec.mec.gov.br/images/stories/pdf/eixo_prod_alim/tec_alim/181012_micr o_alim.pdf>. Acesso em: 01 mai. 2013.

DOMARESKI, J.L.; BANDIERA, N.S.; SATO, R.T.; ARAGON, L.C.; SANTANA, E.H.W. Avaliação físico-química e microbiológica do leite UHT comercializado em três países do Mercosul (Brasil, Argentina e Paraguai). Archivos Latinoamericanos de Nutrición, v. 60, n. 3, p. 261-269, 2010.

FRANCO, B.D.G.M.; LANDGRAF, M. Microbiologia dos Alimentos. São Paulo: São Paulo, 2008.

JAY, J.M. Microbiologia de alimentos. Rio Grande do Sul: Porto Alegre, 2005.

NASCENTES, R.M.; ARAÚJO, B.C. Comparação da qualidade microbiológica de leite cru, pasteurizado e UHT

NERO, L.A.; BELOTI, V.; BARROS, M.A.F. Métodos rápidos e automatizados para enumeração de microrganismos indicadores em leite - utilização no Brasil. Semina: Ci. Agrárias, Paraná: Londrina, v. 21, n. 1, p. 115-126, mar. 2000.

PEREDA, J.A.O.; RODRÍGUEZ, M.I.C.; ÁLVAREZ, L.F.; SANS, M.L.G.; MINGUILLÓN, G.D.G.F.; PERALES, L.H.; CORTECERO, M.D.S. Tecnologia de Alimentos. Rio Grande do Sul: Porto Alegre, 2005.

SILVA, M.C.D.; SILVA, J.V.L.; RAMOS, A.C.S.; MELO, R.O.; OLIVEIRA, J.O. Caracterização microbiológica e físico-química de leite pasteurizado destinado ao programa do leite no Estado de Alagoas. Ciênc. Tecnol. Aliment., Campinas, v. 28, n. 1, p. 226-230, jan./mar. 2008. 
SOUZA, D.P. Avaliação da qualidade higiênico-sanitária do leite utilizado no restaurante escola da Universidade Federal de Pelotas. Rev HCPA, v. 30, n. 1, p. 27-30, 2010.

TAMANINI, R.; SILVA, L.C.C.; MONTEIRO, A.A.; MAGNANI, D.F.; BARROS, M.A.F.; BELOTI, V. Avaliação da qualidade microbiológica e dos parâmetros enzimáticos da pasteurização de leite tipo "C" produzido na região norte do Paraná. Semina: Ciências Agrárias, Paraná: Londrina, v. 28, n. 3, p. 449-454, jul./set. 2007. 